\title{
Cue-Induced Dopamine Release Predicts Cocaine Preference: Positron Emission Tomography Studies in Freely Moving Rodents
}

\author{
Wynne K. Schiffer, ${ }^{1,2}$ Courtney N. B. Liebling, ${ }^{1}$ Corinne Reiszel, ${ }^{1}$ Jacob M. Hooker, ${ }^{1}$ Jonathan D. Brodie, ${ }^{2}$ and \\ Stephen L. Dewey ${ }^{1,2}$ \\ ${ }^{1}$ Medical Department, Brookhaven National Laboratory, Upton, New York 11973, and 2Department of Psychiatry, New York University School of Medicine, \\ New York, New York 10016
}

Positron emission tomography studies in drug-addicted patients have shown that exposure to drug-related cues increases striatal dopamine, which displaces binding of the $\mathrm{D}_{2}$ ligand, $\left[{ }^{11} \mathrm{C}\right]$-raclopride. However, it is not known if animals will also show cue-induced displacement of $\left[{ }^{11} \mathrm{C}\right]$-raclopride binding. In this study, we use $\left[{ }^{11} \mathrm{C}\right]$-raclopride imaging in awake rodents to capture cue-induced changes in dopamine release associated with the conditioned place preference model of drug craving. Ten animals were conditioned to receive cocaine in a contextually distinct environment from where they received saline. Following conditioning, each animal was tested for preference and then received two separate $\left[{ }^{11} \mathrm{C}\right]$-raclopride scans. For each scan, animals were confined to the cocaine and/or the saline-paired environment for the first $25 \mathrm{~min}$ of uptake, after which they were anesthetized and scanned. [ $\left.{ }^{11} \mathrm{C}\right]$-raclopride uptake in the saline-paired environment served as a within-animal control for uptake in the cocaine-paired environment. Cocaine produced a significant place preference $(p=0.004)$ and exposure to the cocaine-paired environment decreased $\left[{ }^{11} \mathrm{C}\right]$-raclopride binding relative to the saline-paired environment in both the dorsal $(20 \% ; p<0.002)$ and ventral striatum $(22 \% ; p<0.05)$. The change in $\left[{ }^{11} \mathrm{C}\right]$-raclopride binding correlated with preference in the ventral striatum $\left(R^{2}=-0.87 ; p=0.003\right)$. In this region, animals who showed little or no preference exhibited little or no change in $\left[{ }^{11} \mathrm{C}\right]$-raclopride binding in the cocaine-paired environment. This noninvasive procedure of monitoring neurochemical events in freely moving, behaving animals advances preclinical molecular imaging by interrogating the degree to which animal models reflect the human condition on multiple dimensions, both biological and behavioral.

\section{Introduction}

Clinical positron emission tomography (PET) studies in drugabusing populations and in healthy controls have shown that exposure to drug-associated cues increases brain concentrations of the neurotransmitter dopamine, which displaces striatal binding of the dopamine receptor ligand, $\left[{ }^{11} \mathrm{C}\right]$-raclopride (Volkow et al., 2006; Wong et al., 2006; Boileau et al., 2007). This response mimics the effects of psychostimulants themselves on the brain, producing a similar magnitude of dopamine release as cocaine or amphetamine (Schlaepfer et al., 1997; Boileau et al., 2007). Moreover, the degree to which drug-associated cues increase brain dopamine strongly correlates with individual differences in the

Received Oct. 27, 2008; revised Feb. 20, 2009; accepted March 5, 2009.

This work was performed at Brookhaven National Laboratory under contract no. DE-ACO2-98CH10886 with the Department of Energy and supported by its Office of Biological and Environmental Research. Additional funds were provided by the Department of Energy (LDRD 06-026 to W.K.S.) and National Institutes of Health (DA15041 and DA22346 to S.L.D.). We are especially grateful for helpful discussions with Drs. Joanna Fowler, Jean Logan, David Alexoff, and Nora Volkow. These studies would not have been possible without advice and continued assistance from Brookhaven National Laboratory (BNL) Health Physics Representatives Kimberly Wehunt and Cheryl Burns. We also appreciate the radiosynthesis efforts of Colleen Shea, Lisa Muench, and Youwen Xu and technical assistance from Vinal Patel, James Anselmini, and Barry Laffler in the BNL Chemistry Department.

Correspondence should be addressed to Dr. Wynne K. Schiffer, Brookhaven National Laboratory, Chemistry Building 555, Upton, NY 11973. E-mail: wynne@bnl.gov.

DOI:10.1523/JNEUROSCI.5221-08.2009

Copyright $\odot 2009$ Society for Neuroscience $\quad$ 0270-6474/09/296176-10\$15.00/0 rewarding effects of the drugs reported by these patients (Volkow et al., 2006; Wong et al., 2006; Boileau et al., 2007; Volkow et al., 2008). Thus, human studies using $\left[{ }^{11} \mathrm{C}\right]$-raclopride PET show that exposure to cues associated with drug use produces relatively large increases in synaptic dopamine; the magnitude of this effect not only correlates with parallel behavioral measurements but also rivals the change in dopamine produced by the drugs themselves.

For the most part, animal studies have also shown cueinduced increases in dopamine. Our own investigations using in vivo microdialysis in rodents conditioned to receive cocaine in a distinct environment demonstrated that cocaine-associated environmental cues significantly increase dopamine transmission in the ventral striatum (Gerasimov et al., 2001). Consistent with these findings, Weiss et al. (2000) and Duvauchelle et al. (2000) also used in vivo microdialysis to demonstrate that exposure to drug-associated cues, but not to control cues, significantly increased dopamine efflux in the ventral striatum. Other studies have shown little or no change in extracellular dopamine in response to cocaine-related cues (Brown and Fibiger, 1992; Bradberry et al., 2000), despite conditioned increases in locomotion (Brown and Fibiger, 1992). However rodent microdialysis studies appear to differ from $\left[{ }^{11} \mathrm{C}\right]$-raclopride PET studies in humans by the magnitude of dopamine release. In rodent studies, the magnitude of dopamine released by cue exposure is consistently a 


\section{CPP Pretest \\ Saline/cocaine pairings \\ CPP Test 1 \\ Scan 1 \\ Scan 2 \\ CPP Test 2}
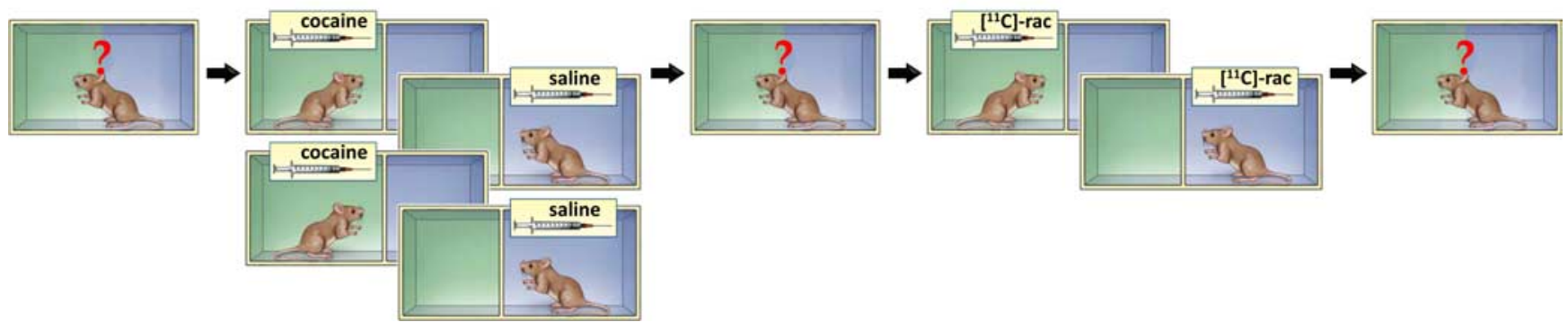

Figure 1. Study design for imaging environmental cue-induced changes in $\left[{ }^{11} \mathrm{C}\right]$-raclopride $\left(\left[{ }^{11} \mathrm{C}\right]\right.$-rac) binding in freely moving animals. In the CPP pretest, animals are tested for an initial chamber preference before any drug exposure. One day after the pretest, animals begin environmental pairing sessions with cocaine $(5.0 \mathrm{mg} / \mathrm{kg}$ i.v.) or saline on alternating days in their least preferred chamber. In this protocol, animals received 10 pairings of saline and 10 pairings with cocaine in contextually distinct environments, or chambers of the CPP apparatus. CPP Test 1 occurred $1 \mathrm{~d}$ after the last pairing session. One day later, animals were confined to one of the two conditioning environments, in which they received intravenous $\left[{ }^{11} \mathrm{C}\right]$-rac instead of intravenous saline or cocaine (Scan 1). After $1 \mathrm{~d}$ of rest, animals were scanned again in the opposite chamber from the first scan (Scan 2). For clarity of presentation, the randomized scan order is not presented; however, the scan order was in fact randomized so that one-half of the animals were scanned first in the saline-paired environment and one-half of the animals were scanned first in the cocaine-paired environment, followed by $1-2 \mathrm{~d}$ of rest and then $\mathrm{Scan} 2$, in which [ $\left.{ }^{11} \mathrm{C}\right]$-raclopride uptake occurred in the opposite conditioning environment. After Scan 2, a second assessment of preference (CPP Test 2) was performed to ascertain the stability of preference through the imaging process.

fraction of that released by the drug itself, whereas human PET studies show a similar magnitude of $\left[{ }^{11} \mathrm{C}\right]$-raclopride displacement (or dopamine release) from both cue and stimulant exposure in addicted patients (Volkow et al., 1999, 2001) and in healthy controls (Boileau et al., 2007). It is not known whether the difference in magnitude reported in human $\left[{ }^{11} \mathrm{C}\right]$-raclopride PET studies versus animal microdialysis studies reflects a difference in measurements of synaptic versus extracellular dopamine, or whether other differences such as species or the types of cues (discrete cues such as paraphernalia are used in human studies whereas animal studies use contextual cues such as floor and wall patterning) explain the lower magnitude of dopamine release associated with cues versus the drugs themselves. The obvious value of animal PET measurements to resolve this controversy has been complicated by the need for anesthesia during scanning, which precludes any investigation of conscious behaviors such as cue exposure.

We have recently developed a new imaging strategy in which biological measures with PET can be directly correlated with behavioral observations in freely moving animals (Patel et al., 2008). In our strategy, radiotracer uptake occurs away from the tomograph with little or no impact on behavior. In the present study, we used this new behavioral imaging strategy to test the hypothesis that exposure to environmental cues previously associated with cocaine will decrease $\left[{ }^{11} \mathrm{C}\right]$-raclopride binding in the striatum of freely moving rats. Animals were first conditioned to receive cocaine in a contextually distinct environment from where they received saline, using the conditioned place preference (CPP) procedure. Animals were tested for preference and then received two $\left[{ }^{11} \mathrm{C}\right]$-raclopride scans: one in which radiotracer uptake occurred in the environment where they received cocaine and a second in the environment in which they received saline. The incentive motivational effects of cocaine, thought to reflect craving for the drug, were measured directly using a place preference test, and this measure was correlated with individual differences in $\left[{ }^{11} \mathrm{C}\right]$-raclopride binding between the two environments.

\section{Materials and Methods}

Study design

The study design is depicted in Figure 1. In these studies, a modified version of the CPP procedure provided an experimental platform to study the conditioned behavioral effects of cocaine with small-animal
PET imaging. As in our previously established CPP protocol (Dewey et al., 1998), animals were first tested for any natural preference for the experimental environments. This pretest was followed by the conditioning phase, during which animals received both cocaine and saline on alternating days. Twenty days after the first conditioning session, after $10 \mathrm{~d}$ of cocaine and $10 \mathrm{~d}$ of saline, animals were tested for their preference for the cocaine-paired environment. After this test, animals were scanned twice with $\left[{ }^{11} \mathrm{C}\right]$-raclopride: once in which uptake occurred in the saline paired environment and once in which uptake occurred in the cocaine paired environment (Fig. 1). The order of the scans was randomized so that one-half the animals underwent $\left[{ }^{11} \mathrm{C}\right]$-raclopride uptake in the saline-paired environment first and the other one-half underwent $\left[{ }^{11} \mathrm{C}\right]$ raclopride uptake in the cocaine-paired environment first. The second scan occurred $1-2 \mathrm{~d}$ following the first, during which $\left[{ }^{11} \mathrm{C}\right]$-raclopride uptake occurred in the opposite environment. Thus, we implemented a within-subject design with a randomized scan order in which both the "control scan" (exposure to the saline-paired environment) and the "challenge scan" (exposure to the cocaine-paired environment) occurred after the cocaine and saline pairings. In this way, any effects of cocaine on dopamine $\mathrm{D}_{2}$ receptors and $\left[{ }^{11} \mathrm{C}\right]$-raclopride binding would similarly influence both scans. One day after the second $\left[{ }^{11} \mathrm{C}\right]$-raclopride scan, animals were again tested for preference. The average preference score from these two tests was used as a covariate with the imaging data and also with the locomotor data, as described below.

\section{Animals}

Fourteen adult male Sprague Dawley rats (240-260 g; Taconic) began the study under an Institutional Animal Care and Use Committee-approved protocol with strict adherence to the National Institutes of Health guidelines. Ten of these animals received all conditioning, testing, and scanning sessions. The remaining four animals either did not receive both cocaine-paired and saline-paired scans $(n=3)$ or the jugular catheter lost patency during the study $(n=1)$. Animals were kept on a $12 / 12 \mathrm{~h}$ light/dark schedule in temperature controlled rooms and were housed individually to prevent damage to the catheter ports by cage mates.

All animals underwent an external jugular vein catheterization using aseptic surgical techniques (Taconic). Polyethylene tubing (PE-50; Becton Dickinson) was exteriorized from the nape of the neck, providing a percutaneous port used postoperatively for daily flushes of the catheter and for administration of all drugs and $\left[{ }^{11} \mathrm{C}\right]$-raclopride. Tubing was flushed every other day with a $10 \%$ heparin/saline solution to maintain line patency.

\section{Drugs}

Cocaine $\mathrm{HCl}$ (Sigma) was dissolved in $0.9 \%$ sodium chloride saline solution and administered at a dose of $5.0 \mathrm{mg} / \mathrm{kg}$ i.v. as a $5-10 \mathrm{~s}$ bolus injection. Anesthesia was induced intravenously with a mixture of ket- 
amine and xylazine (both from Aveco) at a dose of $15 \mathrm{mg} / \mathrm{kg}$ ketamine with $1.5 \mathrm{mg} / \mathrm{kg}$ xylazine, also given as a $5-10 \mathrm{~s}$ bolus.

\section{Radiosynthesis}

$\left[{ }^{11} \mathrm{C}\right]$-Raclopride was synthesized as detailed previously (Ehrin et al., 1986). The average specific radioactivity of $\left[{ }^{11} \mathrm{C}\right]$-raclopride was 7.73 $\mathrm{Ci} / \mu \mathrm{mol}$ (range, $2.6-19.6 \mathrm{Ci} / \mu \mathrm{mol}$ ) at the end of bombardment. Injected doses of $\left[{ }^{11} \mathrm{C}\right]$-raclopride ranged from 97 to $1110 \mu \mathrm{Ci}$ (mean, 730 $\mu \mathrm{Ci}$ ), with a mean injected raclopride mass of $4.27 \pm 3.59 \mathrm{nmol} / \mathrm{kg}$. Using $\left[{ }^{11} \mathrm{C}\right]$-raclopride PET in male Sprague Dawley rats, it has been determined that the in vivo concentration at which one-half of the available $\mathrm{D}_{2}$ receptors are occupied $\left(\mathrm{ED}_{50}\right)$ is $17.1 \mathrm{nmol} / \mathrm{kg}$ (Hume et al., 1995). Using this mean $\mathrm{ED}_{50}$ value of $17.1 \mathrm{nmol} / \mathrm{kg}$ and the method of Hume et al. (1998) to calculate receptor occupancy, the present studies resulted in a maximal $\mathrm{D}_{2}$ receptor occupancy of $11 \%$ by the radiotracer doses.

\section{Place conditioning}

Place-conditioning apparatus. Four standard commercial place conditioning apparatuses (ENV-013; Med Associates) were placed on a table $100 \mathrm{~cm}$ above the floor in a quiet, dimly lit laboratory. Each apparatus consisted of two larger conditioning chambers $(29 \times 25 \mathrm{~cm}$; internal volume of $12 \mathrm{~L}$ ) separated by guillotine doors from a smaller chamber $(11 \times 25 \mathrm{~cm}$; internal volume of $5 \mathrm{~L})$. Each of the two larger chambers was modified with distinct visual and tactile cues to become two separate conditioning environments. One environment had alternating white and black vertical stripes $(2 \mathrm{~cm}$ wide, $2 \mathrm{~cm}$ apart) with a wire-mesh floor (1-mm-diameter stainless steel thread-weaved into $4 \times 4 \mathrm{~mm}$ squares) above orange paper flooring. The other environment had solid black walls with floors of stainless steel rods (4-mm-diameter stainless steel rods spaced $8 \mathrm{~mm}$ apart) above black paper flooring. The third, middle environment had smooth gray walls and a smooth PVC floor. Clear Plexiglas lids covered all three environments and allowed digital recording and remote observation during conditioning and testing. Each lid had standard holes for air and one larger hole $(2 \mathrm{~cm}$ diameter $)$ in the center for injection lines.

Above the table, a video camera (Sony Handycam DCR HC96 DV Camcorder) digitally recorded conditioning, testing, and imaging sessions. Locomotor activity and preference data were analyzed using an automated, computerized scoring system (TopScan version 1.0; Clever Sys.).

Place conditioning procedures. Cocaine was chosen for this study due to its ability to produce a place preference in our laboratory (Dewey et al., 1998) and also because we have previously shown with in vivo microdialysis that exposure to a cocaine-paired environment increases extracellular DA in the ventral striatum (Gerasimov et al., 2001). Like our previous study, each place conditioning experiment consisted of three phases: preconditioning, conditioning, and preference testing. To demonstrate the rewarding properties of the drug (and not the environment), our procedure used a biased method for drug conditioning. In this method, animals were paired with cocaine in their least preferred preconditioning environment.

Before each testing or conditioning session, polyurethane tubing was connected to the jugular vein catheter port (positioned in the infrascapular dorsal midline) in unrestrained animals as they were allowed free movement in their home cage. The size of the tubing was fixed $(0.64 \mathrm{~mm}$ inner diameter, $30 \mathrm{~cm}$ in length, $\sim 100 \mu \mathrm{l}$ of volume) to maintain a constant dead volume and to provide sufficient slack to permit free movement in either the animals' home cage or in any of the conditioning environments. The tubing was attached at one end to a 23G blunt luer hub (Hamilton Kel-F Hub, Point Style 3 with dimensions of $0.64 \mathrm{~mm}$ outer diameter, $51 \mathrm{~mm}$ length and a volume of $4.3 \mu \mathrm{l}$; Hamilton Company) and at the other end to 23 gauge stainless steel tubing, $0.5 \mathrm{~cm}$ in length, which was inserted into the animal's catheter port. A syringe containing heparinized saline was attached to the luer hub when the polyurethane tubing was not in use. During uptake of the radiotracer on a given scan day, the whole unit was taped to the outside of the home cage or conditioning environment. Because the line extended from the infrascapular dorsal midline of the animal up through the Plexiglas lids, ani- mals were not encumbered by the line and only rarely became tangled or tried to chew the tubing.

Preconditioning phase. Animals were handled for $2 \mathrm{~d}$ to habituate them to the researcher and to minimize stress during the preconditioning test (pretest). After $2 \mathrm{~d}$ of habituation, each animal received a pretest to determine whether each animal had a preexisting preference for either of the conditioning environments. For the pretest, animals were placed in the middle, neutral chamber of the place-preference apparatus with the doors closed for $5 \mathrm{~min}$. After the $5 \mathrm{~min}$ acclimation phase, the doors were opened, and the animals were allowed free access to all conditioning environments for $20 \mathrm{~min}$. Time spent in each environment was videotaped and digitally analyzed to determine the amount of time (in seconds) spent in each environmental chamber. On the basis of this data, animals were later conditioned to cocaine in the least preferred environment. No cocaine was administered during this phase, the total duration of which was $3 \mathrm{~d}$.

Conditioning phase. During conditioning, animals received cocaine $(5.0 \mathrm{mg} / \mathrm{kg})$ or saline in cue-specific environments on alternating days. Before each conditioning session, rats were weighed to calculate the appropriate drug dose and to monitor weight gain/loss. For each of these pairing sessions, catheter tubing was inserted into the catheter ports when animals were in the home cage. Animals were then transported from their home cage to the cue-specific environment. Once in the environment, the catheter line was extended through the hole in the Plexiglas lid, and the syringe containing saline was replaced with a syringe containing the dose of cocaine or saline (volume, $\sim 0.3-0.4 \mathrm{ml}$ ), depending on the conditioning session. Catheters were flushed immediately after injection with a saline solution that contained $0.1 \%$ heparin. Rats were then confined to each environment for $30 \mathrm{~min}$, after which animals were returned to their home cage, and the catheter ports were plugged. All conditioning sessions were videotaped and digitally analyzed to determine the total distance (in millimeters) traveled during each pairing as an index of locomotion.

Preference test. The CPP test was identical to the pretest described above. One day after the last pairing, drug-free animals were given free access to all conditioning chambers for $20 \mathrm{~min}$. Time spent in each environment was videotaped and digitally analyzed to determine the amount of time (in seconds) spent in each chamber. Each animal received two preference tests, the first occurred $1 \mathrm{~d}$ before $\left[{ }^{11} \mathrm{C}\right]$-raclopride scanning (Fig. 1, CPP Test 1), and the second occurred $1 \mathrm{~d}$ after the last $\left[{ }^{11} \mathrm{C}\right]$ raclopride scan (Fig. 1, CPP Test 2). This was done to ensure that the scanning process did not interfere with the development of conditioned behaviors. Between the first and second postconditioning preference tests, animals were anesthetized twice and had an additional day between scans to recover from the effects of the anesthesia. This meant that the second $\left[{ }^{11} \mathrm{C}\right]$-raclopride scan (Fig. 1, Scan 2) occurred as many as $4 \mathrm{~d}$ after the last cocaine pairing ( $1 \mathrm{~d}$ for CPP Test 1 plus $2 \mathrm{~d}$ of scanning separated by $1 \mathrm{~d}$ of rest). To account for this variability, we randomized the scan order so that some animals underwent $\left[{ }^{11} \mathrm{C}\right]$-raclopride uptake in the saline-paired environment first and $\left[{ }^{11} \mathrm{C}\right]$-raclopride uptake in the cocaine-paired environment second (and vice versa); however, the second preference test was necessary to ensure that the behavioral effects of conditioning were maintained through this process. All preference testing sessions were videotaped and digitally analyzed to determine the total duration (in seconds) spent in each conditioning environment as an index of drug seeking or preference.

\section{Conditioned locomotion}

All conditioning sessions were videotaped and digitally analyzed to determine the total distance (in millimeters) traveled during each pairing session as an index of locomotion. Locomotor activity was also measured during $\left[{ }^{11} \mathrm{C}\right]$-raclopride uptake, when animals were confined to either the saline or the cocaine-paired environment. Because the scanning sessions were identical to the conditioning sessions in every way, except the actual drug administered (instead of cocaine or saline, animals received a nonpharmacologically active dose of $\left[{ }^{11} \mathrm{C}\right]$ raclopride and were confined to one of the two conditioning environments), locomotor activity was measured during the scanning ses- 
sions (specifically, during $\left[{ }^{11} \mathrm{C}\right]$-raclopride uptake), and this was taken as an index of conditioned locomotion.

\section{Positron emission tomography imaging}

After the environmental pairings and preference test described above, all animals received at least two $\left[{ }^{11} \mathrm{C}\right]$-raclopride PET scans. For each scan, $\left[{ }^{11} \mathrm{C}\right]$-raclopride uptake occurred as animals were confined to one of the two cue-specific environments, after which animals were anesthetized, placed in the PET gantry, and scanned. $\left[{ }^{11} \mathrm{C}\right]$-raclopride scans were carried out in a randomized order as described in Study Design.

Behavioral imaging protocol. The $\left[{ }^{11} \mathrm{C}\right]$-raclopride imaging protocol was specifically designed to resemble the protocol used for the conditioning phase of the CPP experiments described above (Fig. 1). Instead of cocaine or saline, the animals received $\left[{ }^{11} \mathrm{C}\right]$-raclopride. For each imaging session, catheter lines were inserted while the animals were in their home cage and animals were then transported from their home cage to the cue-specific environment, where, the catheter line was extended from the animal out through the hole in the Plexiglas lid. Next, the saline syringe was replaced with a syringe containing a predetermined dose of $\left[{ }^{11} \mathrm{C}\right]$-raclopride in a fixed volume of $0.3-0.6 \mathrm{ml}$. In all cases, $\left[{ }^{11} \mathrm{C}\right]-$ raclopride was administered as a 5-10 s i.v. bolus injection flushed immediately after with $0.2 \mathrm{ml}$ of heparinized saline. The tubing was loosely taped to the side of the conditioning chamber. Rats were allowed to move undisturbed but confined to the cue-specific environment for $25 \mathrm{~min}$ of radiotracer uptake, after which the heparinized saline syringe was replaced with a syringe containing a mixture of ketamine and xylazine ( $10 \%$ xylazine in $100 \mathrm{mg} / \mathrm{ml}$ ketamine). A dose of $15 \mathrm{mg} / \mathrm{kg}$ ketamine with $1.5 \mathrm{mg} / \mathrm{kg}$ xylazine was administered as a $5-10 \mathrm{~s}$ bolus, and animals were nonresponsive to tail pinch and eyeblink reflex in 5-15 s. Anesthetized animals were then removed from the apparatus and positioned on the bed of the tomograph in a nylon stereotaxic head holding device (Kopf Instruments) adapted for small-animal PET to eliminate attenuation artifact (Schiffer et al., 2006). The unit and the animal were advanced into the center of the PET field of view (automated to $160 \mathrm{~mm}$ forward). Precisely $5 \mathrm{~min}$ after the induction of anesthesia, a dynamic PET acquisition (five $300 \mathrm{~s}$ time frames) commenced for $25 \mathrm{~min}$.

Image acquisition. Images were acquired using a microPET R4 tomograph (Concorde Microsystems), which has a transaxial field of view of $11.5 \mathrm{~cm}$. All animals were positioned in the center of the field of view. Each PET scan included subtraction of random coincidences collected in a delayed time window. Three-dimensional sinograms were converted into two-dimensional sinograms before image reconstruction. Data were corrected for photon scatter using the method of tail-fitting of the projections. The measured attenuation correction method available for this system used a ${ }^{68} \mathrm{Ge}$ point source, which requires very long acquisition times (30-60 $\mathrm{min}$ ) to minimize image noise introduced by transmission scanning, and therefore was not carried out. In general, attenuation correction factors are constant over time and should not change the shape of time activity data. Because the data analysis methods proposed here rely on a ratio of $\left[{ }^{11} \mathrm{C}\right]$-raclopride in a receptor-rich region (the striatum) with a receptor-poor region (the cerebellum), and because the striatum and cerebellum have approximately the same attenuation factor (Discussion in Alexoff et al., 2004), a constant attenuation correction factor for the striatum and cerebellum was not reasoned to be necessary. In line with this decision, we have previously demonstrated that attenuation correction using calibrated segmented image data had no effect on the measured distribution volume ratio (DVR) (Alexoff et al., 2004) and that the estimated binding ratio used here closely follows the DVR as binding potential (DVR-1; Patel et al., 2008). Scatter-corrected sinograms were reconstructed using the maximum likelihood expectation maximization (MLEM) algorithm, which with the 20 iterations usd here yields an image resolution of $\sim 1.5 \mathrm{~mm}$ full width at half-maximum at the center of the field of view. The parameters chosen for MLEM reconstructions were based on a series of experiments in which we established the number of iterations required for convergence, as reported by Vaska et al. (2006). The image pixel size in MLEM reconstructed images was $0.8 \mathrm{~mm}$ transaxially with a $1.21 \mathrm{~mm}$ slice thickness.

Image processing. All images were spatially normalized into a standard space, which we identified as Paxinos and Watson stereotaxic space
(Paxinos and Watson, 1986). As a template, we used the magnetic resonance imaging (MRI) atlas provided by Schweinhardt et al. (2003), which is in stereotaxic space and for which we have previously developed $\left[{ }^{11} \mathrm{C}\right]$ raclopride reference images for spatial preprocessing (Schiffer et al., 2005a). Data voxel size in the Schweinhardt atlas (2003) is scaled by a factor of 10 to enable a one-to-one relationship between the coordinates of the Paxinos atlas and the voxel display in the SPM software package. This also approximates the human brain size, allowing minimal modifications to the default parameter settings in this and other image processing software packages. The first steps were performed using the Pixelwise Modeling software package, PMOD, and included isotropic interpolation and rotation of the raw PET images in space to roughly match the Paxinos atlas. This included sorting each image from left to right, making the $z$-axis perpendicular to the coronal $(\mathrm{Y})$ slice, and a flip of the $x$-axis $180^{\circ}$ around the $z$-axis. Whereas in PMOD, the images were also scaled by a factor of 10 and resampled into a volume ("bounding box") that encompassed the spatial extent of the scaled Schweinhardt atlas, which was -80 to $+80 \mathrm{~mm}$ in the $X$-dimension (negative to the left of the midline and positive to the right), -120 to $10 \mathrm{~mm}$ in the $Y$-dimension (posterior to anterior), and -156 to $+60 \mathrm{~mm}$ in the $Z$-dimension (ventral to dorsal). The template provided by Schweinhardt et al. (2003) swaps the $Y$ and $Z$ dimensions to provide a layout that accommodates the SPM software package. In this template, the zero-reference plane was set to bregma, resulting in an image origin at $40.5 \times 78.5 \times 60.5(X \times Y \times Z)$ in pixel space. The scaled voxel size was $2 \times 2 \times 2 \mathrm{~mm}$ (actual voxel size, $0.2 \times 0.2 \times 0.2 \mathrm{~mm}$ ), with an image volume of $80 \times 63 \times 108$ voxels.

Region of interest (ROI) analysis was performed using an in-house ROI template implemented with the PMOD software package. ROIs for PET studies were chosen based on previous guidelines provided for primates by Black et al. (2004) and recently described for rodent PET data (Dalley et al., 2007). Rather than outlining the entire structure on the MRI template, this approach minimizes the effects of spillover by using spheres placed at the stereotaxic center of the dorsal and ventral striata, measuring $2 \mathrm{~mm}$ in diameter (left and right striata were combined; coordinates for the center of the dorsal striatal ROIs were $\pm 2.5 \mathrm{~mm}$ lateral to bregma, $+0.5 \mathrm{~mm}$ anterior to bregma, and $4 \mathrm{~mm}$ below bregma, while coordinates for the ventral striatal ROIs were $\pm 0.5 \mathrm{~mm}$ lateral to bregma, $+1.0 \mathrm{~mm}$ anterior to bregma, and $6 \mathrm{~mm}$ below bregma). Combining the left and right dorsal and ventral striatal ROIs gave two striatal regions with volumes of $8336 \mathrm{~mm}^{3}$ each, containing 1042 voxels. A single bilateral cerebellar region (volume, $9232 \mathrm{~mm}^{3}$ with center coordinates at $\pm 0.0,-12.5$, and $-6.0 \mathrm{~mm}$ in the $X, Y$, and $Z$ dimensions) was used as a reference region due to its low $\mathrm{D}_{2}$ receptor density (Wagner et al., 1983; Farde et al., 1986). ROIs are shown by volumetric rendering in supplemental Figure 2 (available at www.jneurosci.org as supplemental material).

ROI quantitation. The primary dependent variable in PET-imaging studies is the ratio of the distribution of radioligand in a receptor-rich region compared with its distribution in a region devoid of receptors. This ratio, termed the distribution volume ratio, provides a unitless number representing the ratio of receptor density to receptor affinity. With $\left[{ }^{11} \mathrm{C}\right]$-raclopride, changes in the binding ratio reflect changes in synaptic dopamine levels. Increases in dopamine decrease $\left[{ }^{11} \mathrm{C}\right]$ raclopride binding, whereas decreases in dopamine will increase $\left[{ }^{11} \mathrm{C}\right]$ raclopride binding (Dewey et al., 1993). We have previously shown that the binding ratio faithfully reflects the distribution volume ratio when calculated as $\mathrm{BR}=(\mathrm{ST}-\mathrm{CB}) / \mathrm{CB}$, in which $\mathrm{BR}$ is the binding ratio, $\mathrm{ST}$ is the striatal ROI, and CB is the cerebellar ROI (Patel et al., 2008). The change in $\mathrm{BR}$ between the saline-paired environment $\left(\mathrm{BR}_{\mathrm{SAL}}\right)$ and the cocaine-paired environment $\left(\mathrm{BR}_{\mathrm{COC}}\right)$ was calculated as $\left[\left(\mathrm{BR}_{\mathrm{COC}}-\right.\right.$ $\left.\left.\mathrm{BR}_{\mathrm{SAL}}\right) / \mathrm{BR}_{\mathrm{SAL}}\right] \times 100$.

\section{Statistical analysis}

The conditioning procedure featured in the present study included a number of methodological modifications not used in previous studies of this nature. For instance, along with intravenous cocaine and saline delivery, this procedure involved several imaging sessions that included administration of radiotracer and anesthesia. Because all rats received both treatments, this enabled within-subject comparisons of the data. 
The within-subjects design yields greater statistical power and reduces the number of subjects needed to conduct experiments.

CPP data were quantitated using a preference score, which is the time spent in the saline-paired environment subtracted from the time spent in the cocaine-paired environment. Preference was defined as a significant increase in time spent in the cocaine-paired environment, determined with a one-way repeated measures ANOVA, followed by a post hoc Bonferroni-corrected Student's $t$ test to assess the significance of the ANOVA. The level of significance for all statistical tests was $p<0.05$.

Locomotor data were quantitated as distance (in millimeters) traveled during each pairing session. These data provided an index of the acute effects of cocaine and saline to ensure that the dose of cocaine was pharmacologically active and that the saline administration did not produce unexpected effects on animal behavior. For each animal after each pairing session, the distance traveled was plotted against time and an area under the curve (AUC) provided the final outcome measure. AUC data were grouped and analyzed using a two-way repeated measures ANOVA with factors of drug (cocaine or saline) and time (pairing day). Bonferroni-corrected Student's $t$ tests were used to determine the significance of the ANOVA.

For the imaging data, two-way repeated measures ANOVA was used to determine whether there were significant differences in dorsal or ventral striata (first factor) between the cocaine or saline-paired environments (second factor). Bonferroni-corrected Student's $t$ tests determined the significance of the ANOVA.

To establish the relationship between behavioral measures and change in $\left[{ }^{11} \mathrm{C}\right]$-raclopride binding, several regression analyses were performed. Scan data from the first scan for all animals were used for this analysis (the second scan data from two animals were not included). The Pearson Product Moment Correlation was used to determine the strength of the association between specific variables of interest. This test was performed to assess the significance of the relationship between preference score and the difference in $\left[{ }^{11} \mathrm{C}\right]$-raclopride binding between the saline-paired and the cocaine-paired environments. The same test was used to determine the relationship between locomotion in each environment (saline-paired versus cocaine-paired) and $\left[{ }^{11} \mathrm{C}\right]$-raclopride uptake. All statistical analyses were performed using the Systat Software package (stat 3.5; Sigma).

\section{Results}

\section{Conditioned place preference}

As a group, the animals showed no initial preference either chamber, measured as the duration of time spent in each chamber during the CPP pretest: $385 \pm 191$ and $409 \pm 259 \mathrm{~s}$ in the black and white chambers, respectively. After conditioning, the first CPP test before scanning (CPP Test 1 ) showed that animals spent significantly more time in the cocaine-paired environment compared with the saline-paired environment: $436 \pm 231$ and $269 \pm$ $76 \mathrm{~s}$ in the saline-paired and cocaine-paired environments, respectively $\left[F_{(1,18)}=11.59 ; p<0.005\right]$. The second CPP test demonstrated that the place preference was maintained through the scanning process, with significantly more time spent in the cocaine-paired environment compared with the saline-paired environment: $401 \pm 227$ and $254 \pm 51 \mathrm{~s}$ in the saline-paired environments, respectively $\left[F_{(1,18)}=9.40 ; p<0.015\right]$. In Figure 2 , these data are presented as the proportional time spent in each pairing environment relative to the total time spent in both pairing environments, which removes the variable of the time spent in the middle, neutral environment. Figure 2 also shows the preference score data, which was the outcome measure correlated with the imaging and locomotor results.

\section{Locomotion}

In each pairing session, cocaine significantly increased the total distance traveled relative to the distance traveled during saline pairings. A two-way repeated measures ANOVA revealed a significant interaction between pairing day and condition $\left[F_{(11,1)}=\right.$

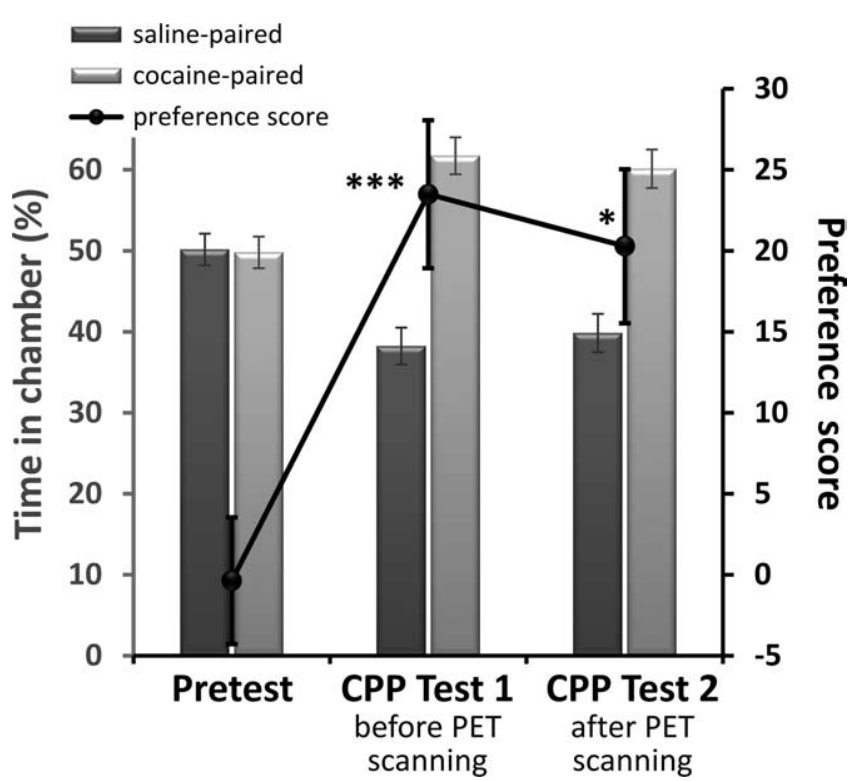

Figure 2. Expression of CPP to cocaine. Proportional time spent in the saline-paired environment (dark gray bars) relative to the cocaine-paired environment (light gray bars) during the preconditioning test (Pretest), after cocaine conditioning (CPP Test 1), and after two $\left[{ }^{11} \mathrm{C}\right]$ raclopride scans separated by $2 \mathrm{~d}$ (CPP Test 2). Percentages are calculated from the total duration (in seconds) spent in both conditioning environments and are presented as mean \pm SEM. Preference score means ( \pm SEM) are presented in red and represent the outcome measure used to identify the relationship between imaging and behavior. Preference scores are calculated by subtracting the proportional time in the saline-paired environment from the proportional time in the cocaine-paired environment. A preference score of 0 indicates no preference. Significant difference from the Pretest preference score was determined with a Student's $t$ test at ${ }^{* * *} p<$ 0.001 , for CPP Test 1 and ${ }^{*} p<0.05$, for CPP Test 2. Preference measurements from each animal were averaged from the two tests to provide a correlate with the imaging data. These data demonstrate that imaging did not affect the development of place preference for cocaine.

3.67; $p<0.001$ ], in which changes in locomotion over time were dependent on condition (saline treatment produced no change in locomotion over time, whereas the locomotor response to cocaine first increased and then decreased with increasing pairings) (supplemental Fig. 1, available at www.jneurosci.org as supplemental material). The mean distance traveled during all of the cocaine pairing sessions was $1677 \pm 295 \mathrm{~mm}$ and for the saline pairings was $713 \pm 59 \mathrm{~mm}$. Together, these data support two points: one, each dose of cocaine was pharmacologically active, and two, tolerance to the locomotor-stimulating effects of cocaine developed over time.

There was also a significant increase in conditioned locomotion measured during $\left[{ }^{11} \mathrm{C}\right]$-raclopride uptake. During these sessions, animals were placed in the conditioning environments (cocaine-paired or saline-paired) and instead of receiving cocaine or saline, they received $\left[{ }^{11} \mathrm{C}\right]$-raclopride. Animals in the cocaine-paired environment traveled a mean distance of $912 \pm$ $158 \mathrm{~mm}$, while animals in the saline-paired environment traveled $639 \pm 77 \mathrm{~mm}$ (significant increase measured by a paired $t$ test; $p<0.0005)$.

\section{PET imaging}

The average time between $\left[{ }^{11} \mathrm{C}\right]$-raclopride injection and microPET scan was $33.33 \mathrm{~min}$. To show that an environment associated with cocaine significantly reduces $\left[{ }^{11} \mathrm{C}\right]$-raclopride binding compared with a neutral environment, we tested for differences in the BR between the "baseline" condition (exposure to the salinepaired environment) and the "challenge" condition (exposure to the cocaine-paired environment). $\left[{ }^{11} \mathrm{C}\right]$-Raclopride binding was 
Table 1. Cue-induced changes in striatal $\left[{ }^{11} \mathrm{C}\right]$-raclopride binding in freely moving animals

\begin{tabular}{|c|c|c|c|c|c|c|}
\hline \multirow[b]{2}{*}{ Condition } & \multicolumn{3}{|c|}{$(\mathrm{ST}-\mathrm{CB}) / \mathrm{CB}($ mean $\pm \mathrm{SD})$} & \multicolumn{3}{|c|}{$\% \Delta$ from saline-paired environment (mean \pm SD) } \\
\hline & Dorsal & Ventral & Combined & Dorsal & Ventral & Combined \\
\hline $\begin{array}{l}\text { Saline-paired environment } \\
\text { Cocaine-paired environment }\end{array}$ & $\begin{array}{l}6.0 \pm 1.2 \\
4.8 \pm 0.5^{* *}\end{array}$ & $\begin{array}{l}3.0 \pm 0.9 \\
2.4 \pm 0.6^{*}\end{array}$ & $\begin{array}{l}4.3 \pm 1.1 \\
3.5 \pm 0.4^{* *}\end{array}$ & $-20.1 \pm 14.3$ & $-21.5 \pm 10.0$ & $-20.8 \pm 12.1$ \\
\hline
\end{tabular}

${ }^{*} p<0.05$, significant difference from saline-paired environment; ${ }^{* *} p<0.01$, significant difference from saline-paired environment.

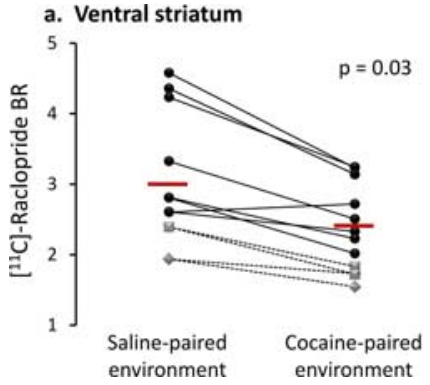

b. Dorsal striatum

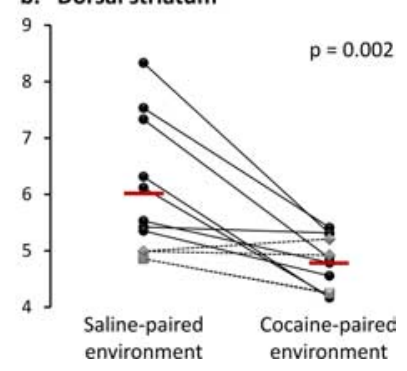

Figure 3. Effects of conditioned cue exposure on striatal $\left[{ }^{11} \mathrm{C}\right]$-raclopride BRs. Exposure to an environment previously paired with cocaine produced significant decreases in [ $\left.{ }^{11} \mathrm{C}\right]$-raclopride striatal binding ratios in both the ventral $(\boldsymbol{a})$ and dorsal $(\boldsymbol{b})$ striatum when compared with exposure to a neutral, saline-paired environment. Mean $\left[{ }^{11} \mathrm{C}\right]$-raclopride BRs in each condition are indicated by a solid line, and the significance is given as calculated from a paired $t$ test. Two of the 10 animals were scanned twice in the cocaine-paired environment (light gray diamonds and squares, dotted lines), with two additional pairings between scans.

lower when animals were exposed to the cocaine-paired environment than when they were exposed to the saline-paired environment. BR values are given in Table 1 . Two-way repeated measures ANOVA of values obtained from the ROI analysis demonstrated a significant main effect of $\operatorname{scan}\left[F_{(1,9)}=16.5, p<0.005\right]$. Two animals received an additional scan in the cocaine-paired environment after two more pairing sessions (two cocaine pairings and two saline pairings). These animals showed little variability between the two scans (Figs. 3-5, gray diamonds and squares, dotted lines), with a difference of $4.1 \pm 2.1 \%$ in $\left[{ }^{11} \mathrm{C}\right]$-raclopride binding measured from the whole striatum. This is consistent with our previously reported variability of $5 \%$ measured from the whole striatum using the same $\left[{ }^{11} \mathrm{C}\right]$-raclopride imaging protocol in animals that were scanned twice $>5 \mathrm{~d}$ in a neutral environment, without prior cocaine (Patel et al., 2008).

The sensitivity of $\left[{ }^{11} \mathrm{C}\right]$-raclopride binding to competition from endogenous dopamine is at least partly conferred by raclopride's relatively fast dissociation rate and low affinity for dopamine $\mathrm{D}_{2}$ receptors $\left(K_{\mathrm{D}}=1.2 \mathrm{nM}\right)$ (Kohler et al., 1985; Seeman et al., 1989). Because high-mass doses of radiotracer can occupy sufficient number of $\mathrm{D}_{2}$ receptors as to change dopamine dynamics (Schiffer et al., 2005a), it is important to ensure that the dose of $\left[{ }^{11} \mathrm{C}\right]$-raclopride carries with it the lowest possible mass of unlabeled raclopride, resulting in the lowest possible occupancy. This represents a continual compromise for animal PET experiments, because the injected dose of radioactivity must provide sufficient counting statistics for reproducible image quality - a factor that uniquely affects iteratively reconstructed data (see below) - yet higher doses of radioactivity also carry higher masses of unlabeled ligand, leading to higher occupancy of $\mathrm{D}_{2}$ receptors. To complicate things further, we have previously shown that injecting awake, freely moving animals leads to four times less $\left[{ }^{11} \mathrm{C}\right]-$ raclopride uptake into the brain compared with injecting anesthetized animals (Patel et al., 2008). Because our imaging protocol involves anesthesia and image acquisition after 25 min of awake $\left[{ }^{11} \mathrm{C}\right]$-raclopride uptake, carbon-11 counts in the brain were already at their lowest point at the time of measurement.

\section{a. Ventral striatum}

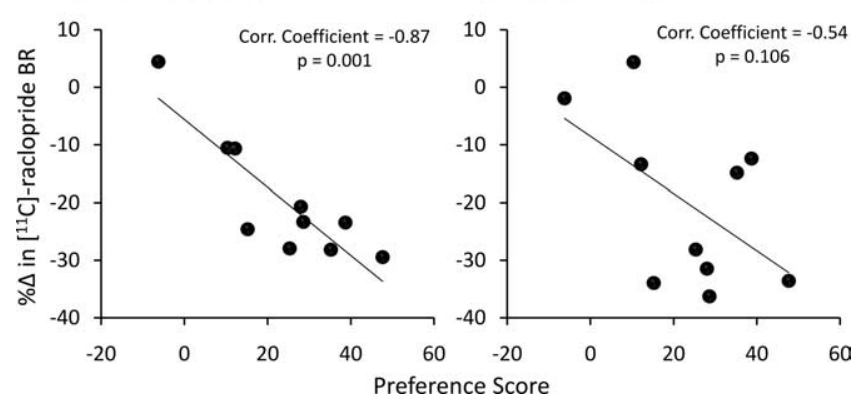

Figure 4. Relationship between preference score and percentage change in $\left[{ }^{11} \mathrm{C}\right]$-raclopride $B R$ in the rat ventral striatum $(\boldsymbol{a})$ or dorsal striatum $(\boldsymbol{b})$ in the cocaine-paired versus salinepaired environments. Preference score represents the difference of the percentage of time spent in the cocaine-paired environment from the percentage of time spent in the saline-paired environment over the $20 \mathrm{~min}$ time interval following free access to both conditioning environments. Preference scores significantly correlated with change in $\left[{ }^{11} \mathrm{C}\right]$-raclopride binding ratio in the ventral striatum but not the dorsal striatum. The strength of the association was quantified with a correlation coefficient (Corr. Coefficient).

This meant that relatively high radiotracer doses were necessary for sufficient counting statistics, which resulted in $8-11 \%$ occupancy of $\mathrm{D}_{2}$ receptors at the highest doses injected. To determine whether receptor occupancy affects the measured binding ratio, we correlated the injected mass of raclopride with binding ratios in the two groups of scans (saline-paired $\left[{ }^{11} \mathrm{C}\right]$-raclopride uptake and cocaine-paired uptake) and found that there was no significant relationship in either group (data not shown), indicating that the mass of raclopride did not affect the measured binding ratios.

Regression analyses revealed that preference for the cocainepaired environment negatively correlated with cocaine cueinduced changes in $\left[{ }^{11} \mathrm{C}\right]$-raclopride $\mathrm{BP}$ in both the ventral and dorsal striata, however this relationship was stronger in the ventral striatum and not significant in the dorsal striatum (Fig. 4). In this regard, a negative relationship was defined by a decrease in the independent variable $\left(\left[{ }^{11} \mathrm{C}\right]\right.$-raclopride binding $)$ as the dependent variable increased (preference score) (Glantz, 2002). Animals that strongly preferred the cocaine-paired environment had larger decreases in $\left[{ }^{11} \mathrm{C}\right]$-raclopride binding compared with animals with weak or no preference for that environment. Figure 5 shows a negative correlation between the change in $\left[{ }^{11} \mathrm{C}\right]$ raclopride binding and the change in locomotion in each environment, measured during $\left[{ }^{11} \mathrm{C}\right]$-raclopride uptake. This association was significant for both the ventral and dorsal striata. Figure 6 shows mean $\left[{ }^{11} \mathrm{C}\right]$-raclopride BR images in rats scanned after exposure to the saline-paired environment and after exposure to the cocaine-paired environment. Weak preferences were defined as those with preference scores $<15$, and strong preferences were defined as those with preference scores $>30$.

\section{Discussion}

In the present study, we used small-animal PET and $\left[{ }^{11} \mathrm{C}\right]-$ raclopride in rats to investigate whether repeated pairing of an 


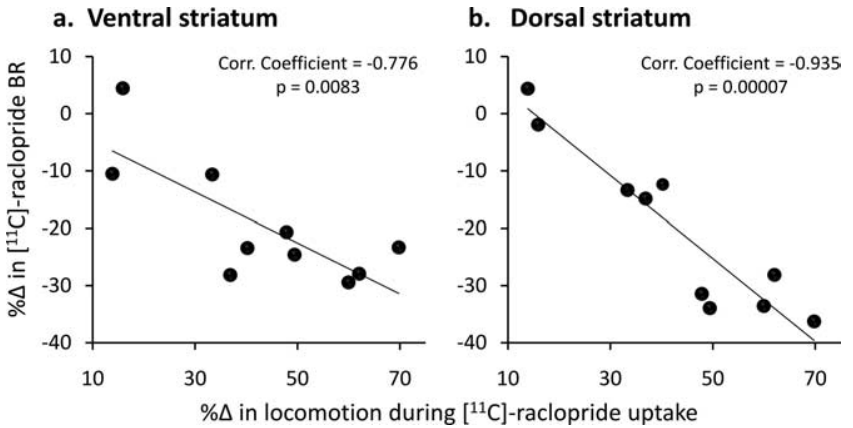

Figure 5. Relationship between the change in $\left[{ }^{11} \mathrm{C}\right]$-raclopride $\mathrm{BR}$ and locomotion in the cocaine- versus saline-paired environments in the ventral striatum $(\boldsymbol{a})$ or the dorsal striatum (b). Locomotion was measured during $\left[{ }^{11} \mathrm{C}\right]$-raclopride uptake in the saline or cocaine paired environments. Percentage change in locomotion between the two environments was calculated as $\left[\left(\mathrm{LOCO}_{\mathrm{COC}}-\mathrm{LOCO}_{S \mathrm{SL}}\right) / \mathrm{LOCO}_{S A L} \times 100\right]$, in which $\mathrm{LOCO}_{\mathrm{COC}}$ is the distance traveled in millimeters in the cocaine paired environment during uptake, and $\mathrm{LOCO}_{S A L}$ is the millimeters traveled in the saline-paired environment during $\left[{ }^{11} \mathrm{C}\right]$-raclopride uptake. The change in $\left[{ }^{11} \mathrm{C}\right]$ raclopride binding correlated significantly with the change in locomotion in both the dorsal and ventral striata. The strength of the association was quantified with a correlation coefficient (Corr. Coefficient).

environment with cocaine would lead to conditioned dopamine release in the striatum during reexposure to the same environment, in the absence of cocaine. We show in vivo evidence for environmental cue-induced release of striatal dopamine in awake, freely moving rats measured with $\left[{ }^{11} \mathrm{C}\right]$-raclopride and small-animal PET. We observed a robust place preference (Fig. 2) accompanied by conditioned increases in locomotion, both of which showed a strong relationship with individual changes in $\left[{ }^{11} \mathrm{C}\right]$-raclopride binding in the ventral striatum between the cocaine-paired versus neutral environment (Figs. 4, 5). In other words, animals with weak or no preference for the cocaine-paired environment have the same dopamine response to this environment as they do to a neutral, saline-paired environment. We also show that animals who strongly prefer the cocaine-paired environment show dramatic differences in dopamine release in this environment compared with the neutral environment.

Because clinical imaging studies are rarely, if ever, performed under anesthesia, it is clearly important to be able to image dopaminergic activity in awake, freely moving animals, allowing a comparison of behavior and physiological responses from preclinical to clinical imaging environments. We therefore developed a technique for imaging dopamine activity in awake, freely moving animals using a conventional animal tomograph. Although the animals are awake during $\left[{ }^{11} \mathrm{C}\right]$-raclopride uptake in this method, they are anesthetized for a short scan afterward, which might complicate comparisons with clinical PET-imaging strategies in which human subjects are not anesthetized during image acquisition.

Nevertheless, the binding ratios for $\left[{ }^{11} \mathrm{C}\right]$-raclopride in the present study were higher than ratios obtained from anesthetized animals in our previous reports (Schiffer et al., 2005a; Patel et al., 2008), and with this, there was a higher between-animal variability (Fig. 3). As evidenced in Figure 4, we maintain that some of this variability lies in natural individual variation; animals who showed little or no preference exhibited little or no change in $\left[{ }^{11} \mathrm{C}\right]$-raclopride binding in the drug-paired environment. However, additional variability may arise from noise in the time activity of ${ }^{11} \mathrm{C}$-raclopride when measured 30-60 min after injection. Because it has been shown with microdialysis that cueinduced increases in dopamine persist for the duration of cue exposure (Duvauchelle et al., 2000; Gerasimov et al., 2001), it may be possible to expose animals to the cue, followed by anesthesia and conventional $\left[{ }^{11} \mathrm{C}\right]$-raclopride scan in which the radiotracer is injected after cue exposure. This would permit the acquisition of a full-time activity curve, at the expense of the signal from changing dopamine concentrations, if changes in dopamine do not persist beyond cue exposure. Even in a conventional $\left[{ }^{11} \mathrm{C}\right]$-raclopride scan in which the entire time-activity curve is obtained from an anesthetized animal, the last 25 min of the scan typically have low counts and more noise, especially in the cerebellum in which there is little specific binding. These data are particularly susceptible to artifact from scattered coincidences, arising from radiotracer accumulation in extracranial structures that typically have much higher uptake than the brain (e.g., Harderian glands, see below). Together with our previous demonstration that four times less radiotracer is reaching the brain (Patel et al., 2008), the critical time points used for quantitation are even more vulnerable to artifact in a region that, by definition, has low radioactivity concentrations. In addition, iterative reconstruction methods such as those used here increase resolution by increasing image contrast (for review, see Vaska et al., 2006), which makes hot areas hotter and cold areas colder. Thus, lower counts and increased noise in the cerebellum, which is the denominator and thus the foundation for quantitating with ratio methods, most likely underlie the higher binding ratios and account for some of the variability in the present studies (Logan et al., 2007).

A related concern was the selection of ROIs, both in terms of size and location. The current study compared the magnitude of cue-induced changes in $\left[{ }^{11} \mathrm{C}\right]$-raclopride binding in two striatal regions in rodents to assess whether there was a differential sensitivity to cues paired with cocaine between the dorsal and ventral striata. Separating the striatum into these subregions permits a direct comparison with in vivo microdialysis measurements of dopamine levels performed using a similar protocol by our group (Gerasimov et al., 2001) and others (Duvauchelle et al., 2000) in which only ventral striatal dopamine levels were measured. In agreement with these previous reports, we also observed a significant increase in ventral striatal dopamine release; however, this was similar to in magnitude to the dopaminergic response from the dorsal striatum (Table 1). Because these structures are small relative to the resolution of our small-animal PET system, such quantitative neuroimaging assessments are also subject to potential bias from the blurring associated with the scanner partial volume effects and from inaccuracies in the PET image coregistration. Whereas iterative reconstruction methods account for some of the partial volume effects (for review, see Vaska et al., 2006), regional PET measurements can still be affected by spilling in of radioactivity from surrounding tissues and dilutional effects from adjacent structures with low radiotracer uptake. In particular, $\left[{ }^{11} \mathrm{C}\right]$-raclopride accumulation in the retro-orbital Harderian glands and/or the dorsal striatum may lead to an overestimation of radioactivity concentrations in the ventral striatum as a result of spillover effects. We expect that ventral striatal ROI values would be similarly influenced by Harderian radioactivity concentrations during both conditions and thus cancel out in relative measurements of change reported here. However, the higher radioactivity concentrations in the dorsal striatal ROI might influence measurements from the ventral striatum, given the higher concentration of $\mathrm{D}_{2} / \mathrm{D}_{3}$ receptors in the dorsal relative to the ventral striatum (Hall et al., 1994). Consistent with previous reports, BR values from the dorsal striatum were approximately twice that of the ventral striatum (Drevets et al., 1999; 
a. Weak Preference

Atlas

template

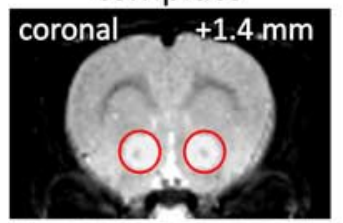

horizontal $1 / .7 .3 \mathrm{~mm}$
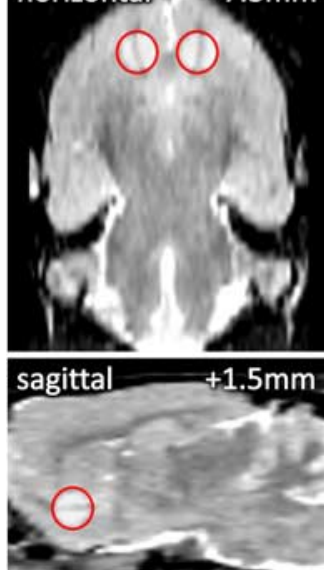

Saline-paired environment
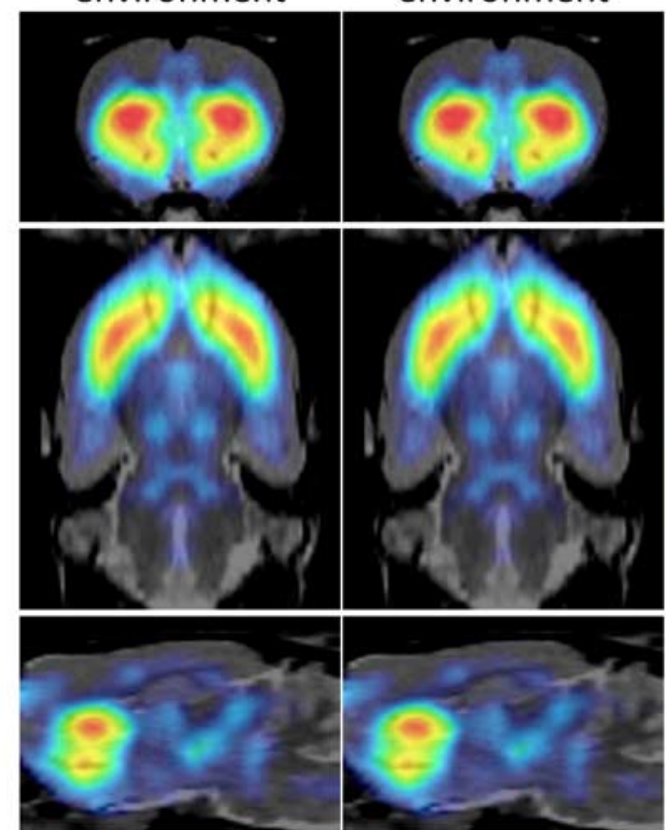

Cocaine-paired environment

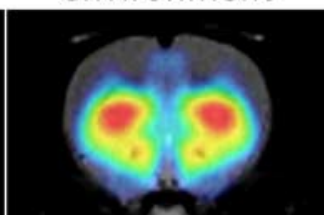

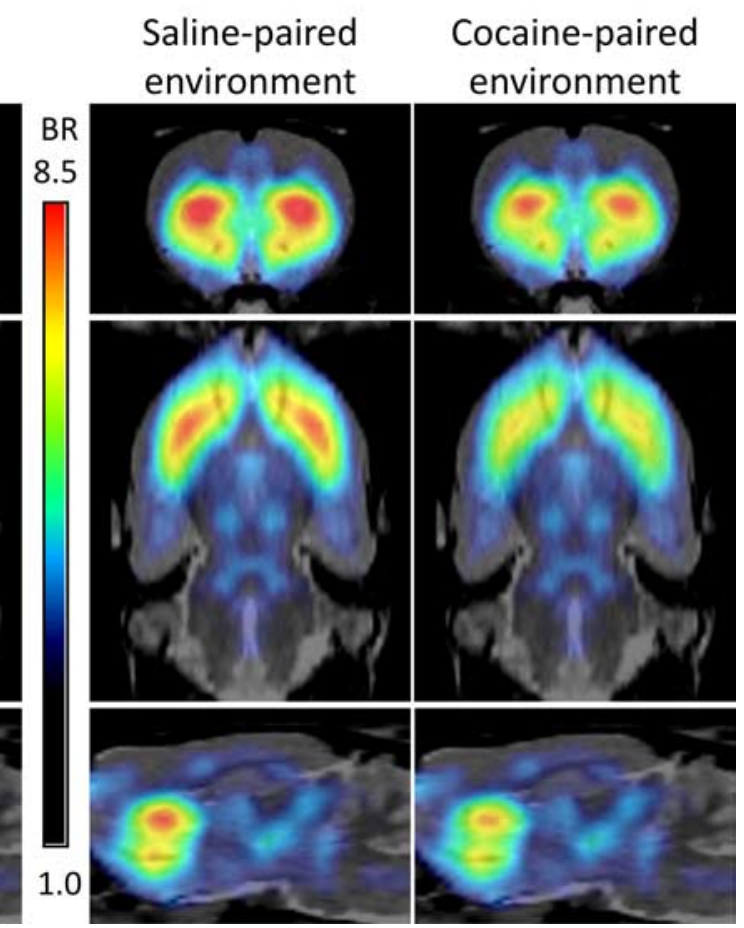

b. Strong Preference

Figure 6. Cue-induced changes in $\left[{ }^{11} \mathrm{C}\right]$-raclopride binding reflect preference for the cocaine-paired environment. In $\boldsymbol{a}$, mean $\left[{ }^{11} \mathrm{C}\right]$-raclopride binding ratio images are shown for animals that showed a weak preference for the cocaine-paired environment (defined as a preference score $<15, n=3$ ). In $\boldsymbol{b}$, mean $\left[{ }^{11} \mathrm{C}\right]$-raclopride binding ratio images are shown for animals that demonstrated a strong preference for the cocaine-paired environment (defined as a preference score $>30, n=5$ ). Parametric images are overlaid on the atlas from Schweinhardt et al. (2003), in which the coronal, horizontal, and sagittal planes are shown. Distance from bregma is given in millimeters on the atlas slice for each orientation, in which the coronal slice is anterior to bregma, the horizontal slice is ventral to bregma, and the sagittal slice is to the right of bregma. The ventral striatal Rol is shown on the atlas images; center coordinates are given in the text. Regional nonspecific uptake of $\left[{ }^{11} \mathrm{C}\right]$-raclopride in lipophilic regions of the brain is similar across all conditions.

Dalley et al., 2007). ROIs centered over the ventral striatum also overlap with the olfactory tubercle. This region has been shown through self-administration studies to be a substrate of cocaine's reinforcing effects, which were blocked by local administration of raclopride (Ikemoto, 2003). Despite the clear separation of radioactivity concentrations in the two regions (Fig. 6, sagittal slices), the axial separation of our dorsal and ventral ROIs was $\sim 0.7 \mathrm{~mm}$ (see supplemental Fig. 2, available at www.jneurosci.org as supplemental material), which is less than the $1.5 \mathrm{~mm}$ axial resolution of our reconstructed images.

These data also show a significant increase in locomotion in the cocaine-paired environment, in the absence of cocaine. Because locomotor measurements occurred during $\left[{ }^{11} \mathrm{C}\right]-$ raclopride uptake, we were able to directly correlate conditioned locomotion and conditioned dopamine release. In fact, we observed a significant relationship between these two variables that was stronger in the dorsal striatum (Fig. 5). This complicates teasing apart the relationship between cocaine-induced changes in conditioned locomotion and cocaine-induced changes in preference for the paired environment. The only comparison we have is to clinical studies in which humans are exposed to drug-related cues during $\left[{ }^{11} \mathrm{C}\right]$-raclopride uptake. However humans can be instructed to be still inside the tomograph, removing confounding influence of locomotion on $\left[{ }^{11} \mathrm{C}\right]$-raclopride binding. Because the present animal studies show similar changes in $\left[{ }^{11} \mathrm{C}\right]-$ raclopride binding as clinical experiments, we maintain that the drugs themselves do not serve as the unconditioned stimuli, rather it is their action within the nervous system that provides the stimulus for an adaptive response (Eikelboom and Stewart,
1982; Stewart et al., 1984; Di Ciano et al., 1998). Accordingly, the increase in dopamine in the striatum could contribute to the actual unconditioned stimulus, and it is the reaction of other neural systems to this neural state that most likely underlie the unconditioned responses of preference for the cocaine-paired environment or increased motor activity. Reliable pairing of the conditioned stimulus with the unconditioned increase in dopaminergic activity elicited by cocaine should enable the conditioned stimulus alone to elicit a similar neural state, through the process of stimulus-stimulus association. This in turn would lead to the activation of the neural systems that underlie specific conditioned responses of preference and enhanced locomotion. The critical point here is that changes in dopaminergic activity are likely to be linked to the stimulus and not the motor response.

Functional neuroimaging in animals represents an essential technology toward understanding the complex relationship between behavior and underlying brain function. As clinical experiments move more into the realm of cognitive and behavioral perturbations of PET tracers, animal studies must follow. For one, behavioral imaging provides a necessary platform to test and refine animal models of human behavior, in which the biological outcome measure is virtually identical across species (e.g., change in radiotracer binding), and the behavioral correlate can be weighed against the biological measure. In other words, behaviors measured in humans and animals are hard to compare and difficult to interpret in terms of producing animal models of a disease that are truly predictive of the human condition (Borsook et al., 2006). In fact, it may not even be valid to assume that behaviors can be directly compared between animals and hu- 
mans. It may be that common underlying neural circuits activated by drugs lead to different behaviors in animals and humans. In that case, using imaging to develop profiles of neural activation corresponding to specific dimensions of dependence might help in establishing the validity of the behavioral model. Imaging provides a strong, independent, and objective link based on the biological underpinnings of the behavior in question. As an example, $\mathrm{CPP}$ is a notoriously difficult procedure to interpret (for review, see Bardo and Bevins, 2000). We have recently used functional imaging with 2 -deoxy-2- $\left[{ }^{18} \mathrm{~F}\right]$-fluoro-D-glucose in rodents to show that the pattern of activations measured during the expression of place preference to methamphetamine strongly resembles the pattern of brain activations in humans who are expecting a psychostimulant challenge (Carrion et al., 2008) and shows less correspondence with the pattern of activation classically associated with drug-craving (for review, see Lingford-Hughes, 2005). Only when individual differences in preference are factored into the imaging data do patterns of activation, which resemble those described in human studies, appear (Carrion et al., 2008). This suggests that expectation plays a key role in the behavioral measure of conditioned preference, and it most likely contributes to the change in dopamine observed here.

The present demonstration of increased striatal dopamine release in response to cocaine-related cues has clinical implications. At this time, there are no known medications to be clinically effective against cue-induced craving. The current study reveals that changes in striatal $\left[{ }^{11} \mathrm{C}\right]$-raclopride binding can predict whether an animal will prefer a specific environment associated with the drug. Unraveling the ways in which neural chemistry forms an animal's predilection for an environment associated with drug use, or vice versa, fosters a whole new world of clinical treatments or therapies aimed at treating the craving that instigates drug seeking and eventually, relapse to drug abuse. The results obtained here support our previous studies (Gerasimov et al., 2001), which show that strategies aimed at inhibiting cueinduced striatal dopamine release in response to the expectation of a drug reward hold promising implications for the treatment of drug addiction (Brodie et al., 2003, 2005; Schiffer et al., 2005b). It is important to note that although this study was designed to model cue exposure in humans, the strategy used here of exposing animals to an environment in which they received cocaine differs from human studies in two fundamental ways. First, cocaine was administered to our animals noncontingently by an experimenter; they did not choose to receive the cocaine. $\mathrm{Hu}$ mans, however, choose to administer the drug, a difference that may influence the biological response to addictive drugs and also to cues associated with their use (Porrino et al., 2002; Volkow et al., 2006). Second, the number of pairing sessions in the present experiment is relatively small compared with the number of times a human might choose to abuse a drug before the formation of a cue association. Nevertheless, this noninvasive procedure of monitoring neurochemical events in freely moving, behaving animals advances preclinical molecular imaging by assessing the degree to which animal models reflect human behavior on multiple dimensions, both biological and behavioral.

\section{References}

Alexoff DL, Vaska P, Logan J (2004) Imaging dopamine receptors in the rat striatum with the MicroPET R4: kinetic analysis of $\left[{ }^{11} \mathrm{C}\right]$-raclopride binding using graphical methods. Methods Enzymol 385:213-228.

Bardo MT, Bevins RA (2000) Conditioned place preference: what does it add to our preclinical understanding of drug reward? Psychopharmacology 153:31-43.

Black KJ, Koller JM, Snyder AZ, Perlmutter JS (2004) Atlas template images for nonhuman primate neuroimaging: baboon and macaque. Methods Enzymol 385:91-102.

Boileau I, Dagher A, Leyton M, Welfeld K, Booij L, Diksic M, Benkelfat C (2007) Conditioned dopamine release in humans: a positron emission tomography $\left[{ }^{11} \mathrm{C}\right]$-raclopride study with amphetamine. J Neurosci 27:3998-4003.

Borsook D, Becerra L, Hargreaves R (2006) A role for fMRI in optimizing CNS drug development. Nat Rev Drug Discov 5:411-424.

Bradberry CW, Barrett-Larimore RL, Jatlow P, Rubino SR (2000) Impact of self-administered cocaine and cocaine cues on extracellular dopamine in mesolimbic and sensorimotor striatum in rhesus monkeys. J Neurosci 20:3874-3883.

Brodie JD, Figueroa E, Dewey SL (2003) Treating cocaine addiction: from preclinical to clinical trial experience with gamma-vinyl GABA. Synapse 50:261-265.

Brodie JD, Figueroa E, Laska EM, Dewey SL (2005) Safety and efficacy of $\gamma$-vinyl GABA (GVG) for the treatment of methamphetamine and/or cocaine addiction. Synapse 55:122-125.

Brown EE, Fibiger HC (1992) Cocaine-induced conditioned locomotion: absence of associated increases in dopamine release. Neuroscience 48:621-629.

Carrion J, Liebling CNB, Dalal R, Alexoff DL, Schiffer WK (2009) Imaging the conditioned behavioral effects of methamphetamine in rodents. Brain Imaging Behav. Advance online publication. Retrieved April 28, 2009. doi: 10.1007/s11682-009-9060-9.

Dalley JW, Fryer TD, Brichard L, Robinson ES, Theobald DE, Laane K, Pena Y, Murphy ER, Shah Y, Probst K, Abakumova I, Aigbirhio FI, Richards HK, Hong Y, Baron JC, Everitt BJ, Robbins TW (2007) Nucleus accumbens $\mathrm{D}_{2 / 3}$ receptors predict trait impulsivity and cocaine reinforcement. Science 315:1267-1270.

Dewey SL, Smith GS, Logan J, Brodie JD, Fowler JS, Wolf AP (1993) Striatal binding of the PET ligand ${ }^{11} \mathrm{C}$-raclopride is altered by drugs that modify synaptic dopamine levels. Synapse 13:350-356.

Dewey SL, Morgan AE, Ashby CRJ, Horan B, Kushner SA, Logan J, Volkow ND, Fowler JS, Gardner EL, Brodie JD (1998) A novel strategy for the treatment of cocaine addiction. Synapse 30:119-129.

Di Ciano P, Blaha CD, Phillips AG (1998) The relation between dopamine oxidation currents in the nucleus accumbens and conditioned increases in motor activity in rats following repeated administration of D-amphetamine or cocaine. Eur J Neurosci 10:1113-1120.

Drevets WC, Price JC, Kupfer DJ, Kinahan PE, Lopresti B, Holt D, Mathis C (1999) PET measures of amphetamine-induced dopamine release in ventral versus dorsal striatum. Neuropsychopharmacology 21:694-709.

Duvauchelle CL, Ikegami A, Castaneda E (2000) Conditioned increases in behavioral activity and accumbens dopamine levels produced by intravenous cocaine. Behav Neurosci 114:1156-1166.

Ehrin E, Gawell L, Hogberg T, Paulis T, Strom P (1986) Synthesis of $\left[\right.$ methoxy- $\left.{ }^{3} \mathrm{H}\right]$ and $\left[\right.$ methoxy- $\left.{ }^{11} \mathrm{C}\right]$-labelled raclopride Specific dopamine- $\mathrm{D}_{2}$ receptor ligands. J Labelled Compd 24:931-940.

Eikelboom R, Stewart J (1982) Conditioning of drug-induced physiological responses. Psychol Rev 89:507-528.

Farde L, Hall H, Ehrin E, Sedvall G (1986) Quantitative analysis of $\mathrm{D}_{2}$ dopamine receptor binding in the living human brain by PET. Science 231:258-261.

Gerasimov MR, Schiffer WK, Gardner EL, Marsteller DA, Lennon I, Taylor SJ, Brodie JD, Ashby CR, Dewey SL (2001) GABAergic blockade of cocaine-associated cue-induced increases in nucleus accumbens dopamine. Eur J Pharm 414:205-209.

Glantz SA (2002) Statistical analysis of trends. In: Primer of biostatistics, Ed 2 (Glantz SA, ed), pp 230-297. New York: McGraw Hill Medical Publishing Division.

Hall H, Sedvall G, Magnusson O, Kopp J, Halldin C, Farde L (1994) Distribution of $\mathrm{D}_{1}$ - and $\mathrm{D}_{2}$-dopamine receptors, and dopamine and its metabolites in the human brain. Neuropsychopharmacology 11:245-256.

Hume SP, Opacka-Juffry J, Myers R, Ahier RG, Ashworth S, Brooks DJ, Lammertsma AA (1995) Effect of L-dopa and 6-hydroxydopamine lesioning on $\left[{ }^{11} \mathrm{C}\right]$-raclopride binding in rat striatum, quantified using PET. Synapse 21:45-53.

Hume SP, Gunn RN, Jones T (1998) Pharmacological constraints associated with positron emission tomographic scanning of small laboratory animals. Eur J Nucl Med 25:173-176. 
Ikemoto S (2003) Involvement of the olfactory tubercle in cocaine reward: intracranial self-administration studies. J Neurosci 23:9305-9311.

Kohler C, Hall H, Ogren SO, Gawell L (1985) Specific in vitro and in vivo binding of $\left[{ }^{3} \mathrm{H}\right]$-raclopride: a potent substituted benzamide drug with high affinity for dopamine $\mathrm{D}_{2}$ receptors in the rat brain. Biochem Pharmacol 34:2251-2259.

Lingford-Hughes A (2005) Human brain imaging and substance abuse. Curr Opin Pharmacol 5:42-46.

Logan J, Alexoff D, Kriplani A (2007) Simplifications in analyzing positron emission tomography data: effects on outcome measures. Nucl Med Biol 34:743-756.

Patel VD, Lee DE, Alexoff DL, Dewey SL, Schiffer WK (2008) Imaging dopamine release with positron emission tomography (PET) and ${ }^{11} \mathrm{C}$ raclopride in freely moving animals. Neuroimage 41:1051-1066.

Paxinos G, Watson C (1986) The rat brain in stereotaxic coordinates. San Diego: Academic.

Porrino LJ, Lyons D, Miller MD, Smith HR, Friedman DP, Daunais JB, Nader MA (2002) Metabolic mapping of the effects of cocaine during the initial phases of self-administration in the nonhuman primate. J Neurosci 22:7687-7694.

Schiffer WK, Alexoff DL, Shea C, Logan J, Dewey SL (2005a) Development of a simultaneous PET/microdialysis method to identify the optimal dose of ${ }^{11} \mathrm{C}$-raclopride for small animal imaging. J Neurosci Methods 144:25-34.

Schiffer WK, Lee DE, Brodie JD, Dewey SL (2005b) Imaging addiction with PET: is insight in sight? Drug Discov Today 10:547-562.

Schiffer WK, Mirrione MM, Biegon A, Alexoff DL, Patel V, Dewey SL (2006) Serial microPET measures of the metabolic reaction to a microdialysis probe implant. J Neurosci Methods 155:272-284.

Schlaepfer TE, Pearlson GD, Wong DF, Marenco S, Dannals RF (1997) PET study of competition between intravenous cocaine and $\left[{ }^{11} \mathrm{C}\right]$ raclopride at dopamine receptors in human subjects. Am J Psychiatry 154:1209-1213.

Schweinhardt P, Fransson P, Olson L, Spenger C, Andersson JL (2003) A template for spatial normalisation of MR images of the rat brain. J Neurosci Methods 129:105-113.

Seeman P, Guan HC, Niznik HB (1989) Endogenous dopamine lowers the dopamine $\mathrm{D}_{2}$ receptor density as measured by $\left[{ }^{3} \mathrm{H}\right]$ raclopride: implications for positron emission tomography of the human brain. Synapse 3:96-97.

Stewart J, de Wit H, Eikelboom R (1984) Role of unconditioned and conditioned drug effects in the self-administration of opiates and stimulants. Psychol Rev 91:251-268.

Vaska P, Rubins DJ, Alexoff DL, Schiffer WK (2006) Quantitative imaging with the micro-PET small-animal PET tomograph. Int Rev Neurobiol 73:191-218.

Volkow ND, Wang GJ, Fowler JS, Logan J, Gatley SJ, Wong C, Hitzemann R, Pappas NR (1999) Reinforcing effects of psychostimulants in humans are associated with increases in brain dopamine and occupancy of $\mathrm{D}_{2}$ receptors. J Pharmacol Exp Ther 291:409-415.

Volkow ND, Wang G, Fowler JS, Logan J, Gerasimov M, Maynard L, Ding Y, Gatley SJ, Gifford A, Franceschi D (2001) Therapeutic doses of oral methylphenidate significantly increase extracellular dopamine in the human brain. J Neurosci 21:RC121.

Volkow ND, Wang GJ, Telang F, Fowler JS, Logan J, Childress AR, Jayne M, Ma Y, Wong C (2006) Cocaine cues and dopamine in dorsal striatum: mechanism of craving in cocaine addiction. J Neurosci 26:6583-6588.

Volkow ND, Wang GJ, Telang F, Fowler JS, Logan J, Childress AR, Jayne M, Ma Y, Wong C (2008) Dopamine increases in striatum do not elicit craving in cocaine abusers unless they are coupled with cocaine cues. Neuroimage 39:1266-1273.

Wagner HNJ, Burns HD, Dannals RF, Wong DF, Langstrom B, Duelfer T, Frost JJ, Ravert HT, Links JM, Rosenbloom SB, Lukas SE, Kramer AV, Kuhar MJ (1983) Imaging dopamine receptors in the human brain by positron tomography. Science 221:1264-1266.

Weiss F, Maldonado-Vlaar CS, Parsons LH, Kerr TM, Smith DL, Ben-Shahar O (2000) Control of cocaine-seeking behavior by drug-associated stimuli in rats: effects on recovery of extinguished operant-responding and extracellular dopamine levels in amygdala and nucleus accumbens. Proc Natl Acad Sci U S A 97:4321-4326.

Wong DF, et al (2006) Increased occupancy of dopamine receptors in human striatum during cue-elicited cocaine craving. Neuropsychopharm 31:2716-2727. 